Article

\title{
On "arogi" buildings' structural system and construction procedure after the 1953 earthquake in Kefalonia
}

\section{Eleni Theotokatou}

NTUA Architect, Athens, Greece, eltheotok@central.ntua.gr

\begin{abstract}
After the series of earthquakes in August 1953, most of Kefalonia's building stock totally collapsed. The buildings that emerged as a result of a collective effort are commonly referred to as «arogi» buildings, with the term arogi meaning help or assistance. In this way, merely referring to these structures is a direct mention to the circumstances under which they were constructed. The reconstruction of the building stock of the island was based in a series of building types proposed from the authorities, and proceeded replacing the richness of the architectural forms that stood before the earthquake, with austere but necessary settlements. Nevertheless, it is these buildings that constitute today's image of the island. This study wishes to introduce us to "arogi" buildings structural system, as it was applied in Kefalonia after 1953 earthquake, with reference to recent bibliography and the recent experience of 2014 earthquake. The purpose of setting the grounds for such a research would be to highlight the effectiveness of this structural system. Moreover, to emphasize the fact that "arogi" buildings and their construction procedure incorporate Kefalonia's recent history and have eventually produced today's available "traditional" architecture of the island.
\end{abstract}

Keywords: arogi buildings; 1953 earthquake; confined masonry; Kefalonia

\section{Introduction}

The Ionian Islands stand in a remarkably seismic area, with Kefalonia literally standing on the Greek trench, i.e. where Eurasian and African lithospheric plates come to meet. Due to its geographical position, all of the islands constantly suffer from earthquakes, whose intensity ranges from innocuous - small intensity earthquakes may occur even on a daily basis for certain periods to extreme [1], such as the 1953 earthquakes.

In August 1953, all the Ionian Islands were severely damaged by series of large earthquakes that lasted about three days [2] (pp. 7-10]. The 1953 earthquakes left Kefalonia mourning for the loss of a great number of people and the majority of its building stock [3] (pp. 43-77). In order for the island to be reconstructed, local authorities and mere individuals had to ask for - and thus received financial and any other kind of help from expatriates, other countries and the Greek state itself [3] (pp. 93-98, 112-133).

Eventually in 1954, the Legislative Decree no. 2933/27-07-1954 (GG162A): On reconstruction of earthquake stricken Ionian Islands, sets the legal framework for the necessary procedures for the reconstruction. Article 13 refers to the "constitution of a committee whose obligation is to decide who would be benefited with financial aid, in order to build an anti-seismic house" [4] (p.241). The construction of "arogi" buildings followed the land redistribution that was certified by the Royal Decree of 8.11.1955 [5]. Having no other recourses, the possession of land was nothing but the first step for the reconstruction. Necessary building materials, plans and relevant studies or mere financial recourses had to be provided by the state, as an aid arogi.

The new houses were to be built following a series of building types proposed from the authorities that could ensure static adequacy but were architecturally unfamiliar: as it concerns spatial manipulation, all ties with tradition were abruptly broken. The locals were not content with the austerity of the proposed designs [3] (p. 222, 247), [6] (p.22) and whenever it was feasible, the 
original designs were adapted from the available engineers. In the public building sector, as Dionusis Zivas puts it: "...for Kefalonia and Ithaki, it was decided that they had to be reconstructed according to the modern architectural forms. The truth is that the case was very tempting and such an opportunity is not often met" [7] (p.44).

The sense of loss is still alive in the Ionian Islands, given that many of the witnesses are still alive and tell the story. In some areas - as in the north of Kefalonia, in old Vlachata, the old village of Farsa etc. - one can still find the remains of pre-seismic buildings or even whole villages abandoned by their inhabitants, who moved nearby and built a completely new settlement. Moreover, nature itself keeps the memory alive, as the seismic activity has never ceased to trouble the broader area.

For Kefalonia, the recent experience of 2014 earthquake that caused extensive building damages especially in Palliki but thankfully no human casualties, not only reminded locals to be in constant vigilance, but drew the engineers' attention as well $[8,9]$. Overall, the 2014 earthquake did not cause structural damage to arogi buildings, given they remained in their original state, not burdened with additional storeys or extended. Their remarkable seismic performance after almost 60 years of constant exposure in seismic tenses and especially under the extremely high accelerations and intensity of 2014 earthquake triggered F. Karantoni and S. Pantazopoulou's further research, whose objective was to compare the confined masonry building method with the traditional unreinforced masonry buildings, as a possible alternative construction method after the earthquake [8,9].

Moreover, apart from their obvious structural value, this paper wishes to point out arogi buildings broader architectural importance. Within the architectural field, plain structures are being set in a specific social and economic framework, acquiring historical meaning.

The real objective of this paper is to open a conversation about arogi buildings, with reference to their structural characteristics as well as placing them in the particular historical context, aiming to stress out their architectural value.

\section{Materials and Methods}

We intend to introduce arogi buildings, both as technical as well as historical objects.

At first we shall try to briefly outline the Kefalonian architectural tradition, as it was formed up until the earthquake of 1953, in order to understand the inhabitants reaction towards the arogi buildings and late modern architectural morphology [6] (pp.22-25).

Following that brief report, the paper refers to the several stages of the reconstruction after the 1953 earthquake: from temporary housing attempts, to the redevelopment of the land and the construction of permanent buildings. All the references above constitute the necessary background in order to proceed examining closely the procedure and the structural system itself of arogi buildings. In order to understand the behavior of reinforced confined masonry (RCM) buildings, we will attempt to compare their basic structural functions to those of reinforced concrete (RC) frames with infill walls, which is widely applied in Greece.

\section{Up to 1953}

The year 1953 met Kefalonian architecture to the point it had reached almost 450 years since the island authorities collaborated with the Venetian Republic in order to prevent the Turkish invasion, an occupation that lasted until 1797. During that period, the venetians respected the established character of the island, as it is expressed through language, religion, customs etc. and at a certain extent its political autonomy.

Prosperity, especially among the aristocracy, allowed for the construction of impressive mansions, whose architecture refers directly to the Venetian baroque. In fact, this historic style was already familiar to Kefalonia: families with significant influence and wealth - i.a. Conte Anninos and Conte Metaxas families [figure 1] - had the means to travel, get acquainted with the Italian baroque style even before the venetian occupation and transplant it in their residences and churches [6] (p.8). Primarily, the Venetian influence can be identified in the way aristocracy residences tend to imitate the Venetian baroque. Gradually, plain mimicry gave way to a "kefalonian" baroque [6] (p.9) [10], 
(p.105) that came up as extrinsic elements - eclectically chosen by the local masters - were continuously modified through practice.

At the same time, the traditional kefalonian house before the earthquake is usually a two-storey - rarely, a three-storey - house, built of local stone-amigdalopetra or pori-and is covered by a wooden structure roof with roman ceramic roof tiles. Most characteristic of kefalonian two-sloped roof is atsoupi - a wall that is formed on the side, as the two slopes of the roof meet - with its usual window that provides light to the storeroom below the roof [11] (p.11) [figure 2].

Many houses built before the earthquake, still stand until today most of them are found in northern Kefalonia and especially around the area of Fiscardo. Unfortunately, most of those buildings suffered severe injuries after 2014 earthquake, the most intense one since 1953 [figure 3].

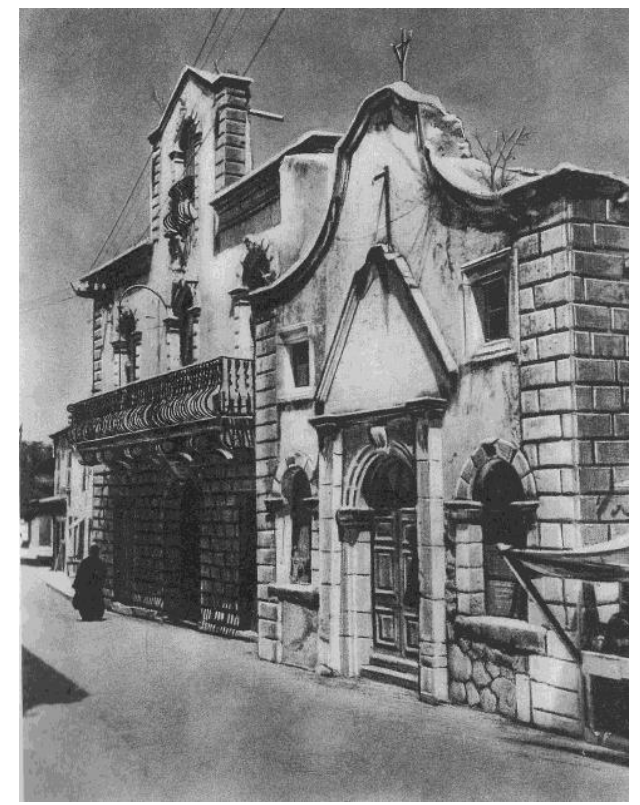

Figure 1. Conte Metaxas house, Argostoli, 1755 (photo. 1949) [6, fig.1] (p.31-I)

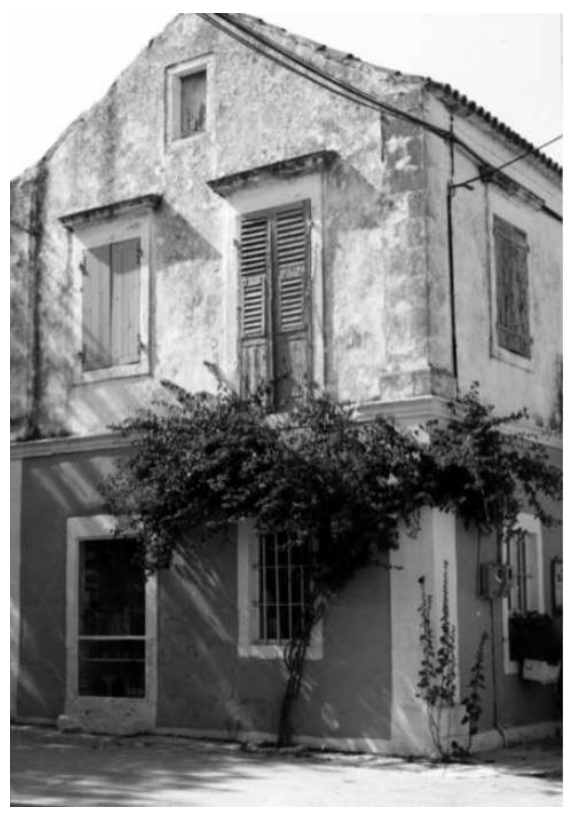

Figure 2. Two-storey house before 1953 earthquake, in [11] (p.12). 


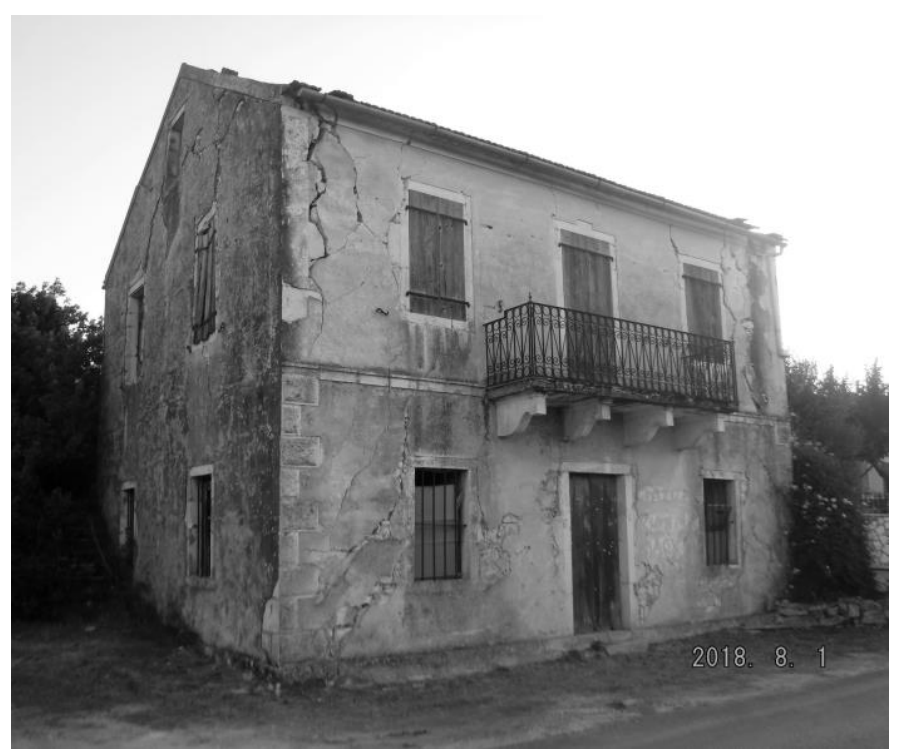

Figure 3. Two-storey house built before the 1953 earthquake near Fiskardo, in present condition.

\section{The Reconstruction}

In order to be reconstructed, the island accepted any available help: the Israeli, American, English and Italian aid came floating as these countries' ships disembarked to the island soon after the great quake, offering precious medical help, food and manpower [4] (pp. 88-99). More or less, it seems that humanitarian aid was self-organized, as native authorities mostly dealt with preventing a migratory wave within the country and long-term planning.

Many crews worked on extensive demolitions - although their extent is often criticized as unnecessary [4] (pp.135-141), [11] (p.57) - and eventually made way for the redistribution of the land and eventually the reconstruction of the island.

As it is expected, housing became a major issue. At first people lived in tents, but as the winter approached the housing problem became crucial. Staying in the moored ships was dropped out as a temporary solution, so people started constructing temporary houses on their own, using timber collected from the ruins. Not long after that, additional timber was imported, along with prefabricated wooden houses that arrived from Scandinavian countries [4] (p.247). A great number of these houses are still used, although they seem to get abandoned in the last twenty years [figure 4].

The legal framework for the redistribution of the land, which was the necessary precondition for the establishment of new permanent settlements, was set about a year later in July 1954 [4] (pp.241245), [6]. Eventually, reconstruction proceeded according to a series of building types, designed by the appointed Ministry. Their design was the result of an international cooperation, between local and corresponding authorities from earthquake stricken areas around the world, which shared their knowledge about earthquake-resistant building methods [4] (p.254).

Up until 1959, when the necessary revision of the anti-seismic regulation was formally ratified [13], the reconstruction proceeded following a series of extensions, additions and modifications of the previously valid regulations. Moreover, in order to deal with the extended scale of the construction projects, the authorities issued a number of more or less practical instructions concerning the execution of the construction works [4] (p.254), [14, 15, 16]. This is an important point to stress, because it seems that the urgency of the situation, as well as the great number of the construction projects, are utterly connected with the absence of strict specifications of the structural system that was finally applied in the housing projects. 


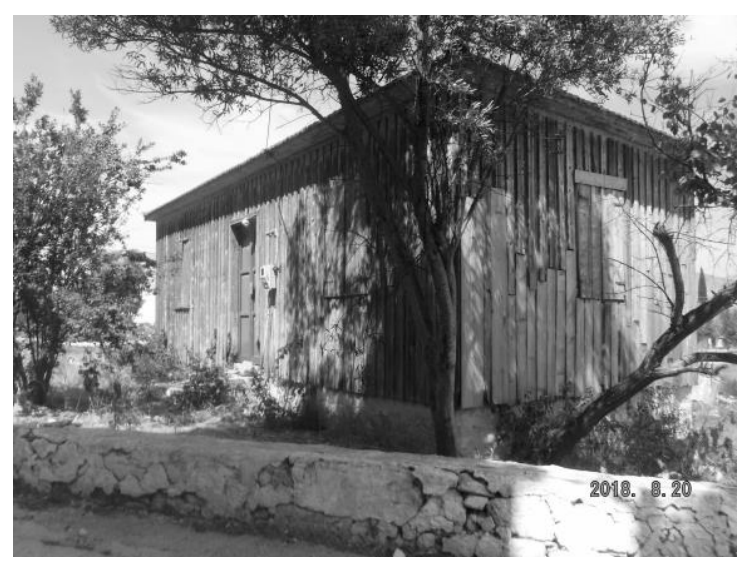

Figure 4. Timber house in Soullaroi, Palliki.

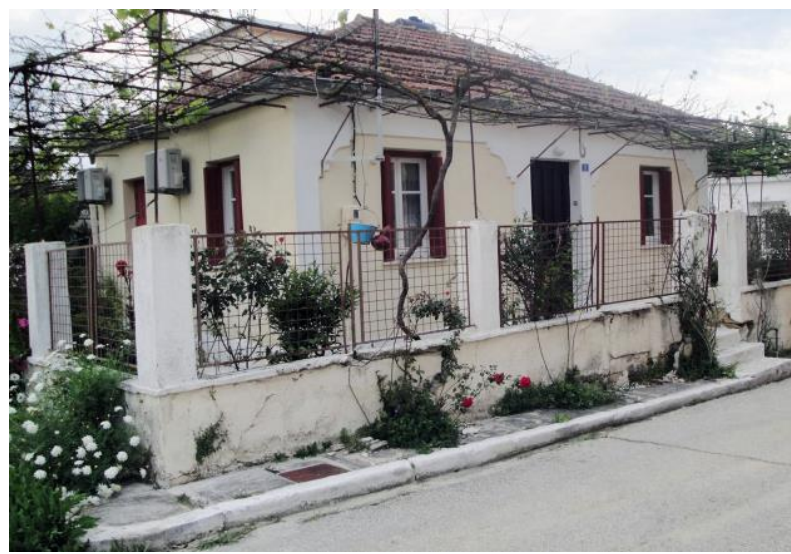

Figure 5. One-storey arogi house in Lixouri after the 2014 earthquake.

\section{On "arogi" construction procedure}

The proposed construction system was applied to several architectural types, in order to serve different types of functional needs among the inhabitants. Each site owner was granted with the complete design (architectural and structural), along with an interest free loan for construction expenses. Alternatively, one could receive the equivalent of the loan, in whole or in part, in building materials only. It is this help on behalf of the state that is noted, when locals call these houses "aroges" [figure 5], for the help they were offered and used at that time.

A variety of thirty-three types were sorted in two general groups: urban and rural types. Among them, twenty-five (25) types were meant for urban and semi-urban settlements and the rest for country houses. Fourteen (14) of the urban types refer to single-storey houses, whose area ranges approximately from $40 \mathrm{~m} 2$ to $80 \mathrm{~m} 2$ and eleven (11) types refer to two-storey buildings, ranging from $40 \mathrm{~m} 2$ to $89 \mathrm{~m} 2$ per floor. In some of the two-storey types - as in type $\mathrm{A} \Sigma-16$, or $\mathrm{A} \Sigma-24$ - architectural design has provided for other building uses than dwelling, as professional services and retail. In those cases, the first floor was meant to serve dwelling needs, while ground floor houses shops or other uses (usually both floors belong to the same owner).

Most of the one-storey and the first floor houses consisted of a living room, two bedrooms, a kitchen and a small bathroom. Some types consisted only of a large everyday living room, a kitchen and a bathroom, but did not provide for any separate bedrooms at all. In those cases - as in type AS9 - a rectangular footprint indicated the intention for a future expansion of the house.

The construction of each building type was supported by a full list of drawings and documents [figures 6,7]. As for the architectural plans, the list contained: different versions of general layouts ground and first floor plan, elevations and section (usually one). Different versions of general layout gave alternative settings, depending on the plot orientation and in order to avoid north orientation for the living room. 
No need to argue that in a case where the whole island is an extended construction plot waiting for the Reconstruction [4] (p.222) [7] (p.24), structural design is crucial. Given the emergency, the state had to ensure that the reconstruction not only would proceed without delay and at minimum cost, but mainly that new buildings would perform efficiently against future quakes. By taking over the elaboration of the design, Greek authorities undertook the responsibility of concluding upon an efficient structural system, primarily able to house the homeless and eventually restore the inhabitants' trust towards a safe everyday life - and the state itself. Moreover, subjecting postearthquake reconstruction to a predefined and centrally designed construction system, the state achieved an essential degree of control over the construction procedure and outcomes - especially when the extent of the reconstruction works was so vast, that the available engineers and construction crews could barely suffice the need for design and construction supervision. In many cases, the citizens themselves had to work for their house to be built, so they should be able to follow a simple and definite building method and at the same time, a flexible one, considering that the "construction crews" were of unspecified composition.

Nevertheless, despite the variety of the building types and the fact that a commission of an engineer was not necessary, many citizens hired a professional in order to adjust predefined design to the specific site or needs of the owner.

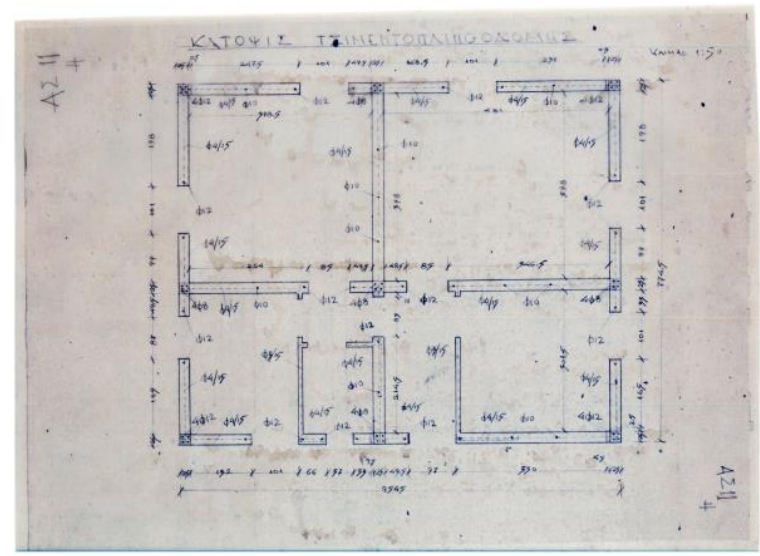

(a)

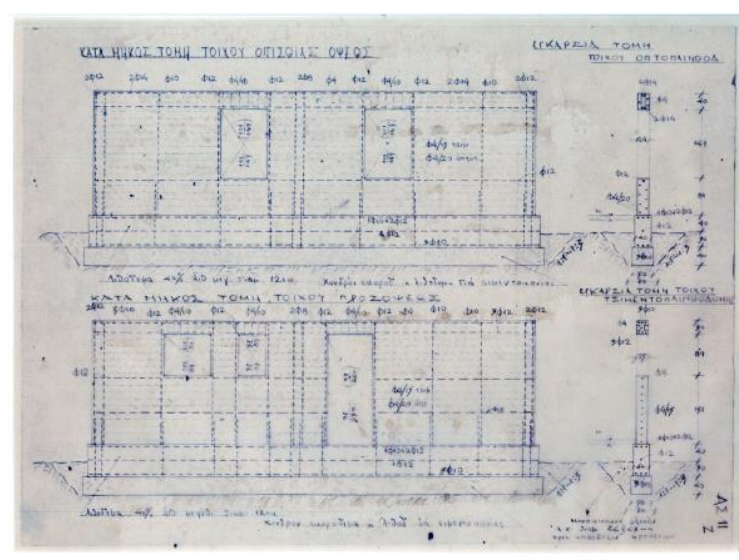

(b)

Figure 6. Confined masonry one-storey house with concrete blocks. (a) Detailed plan; (b) Detailed section.

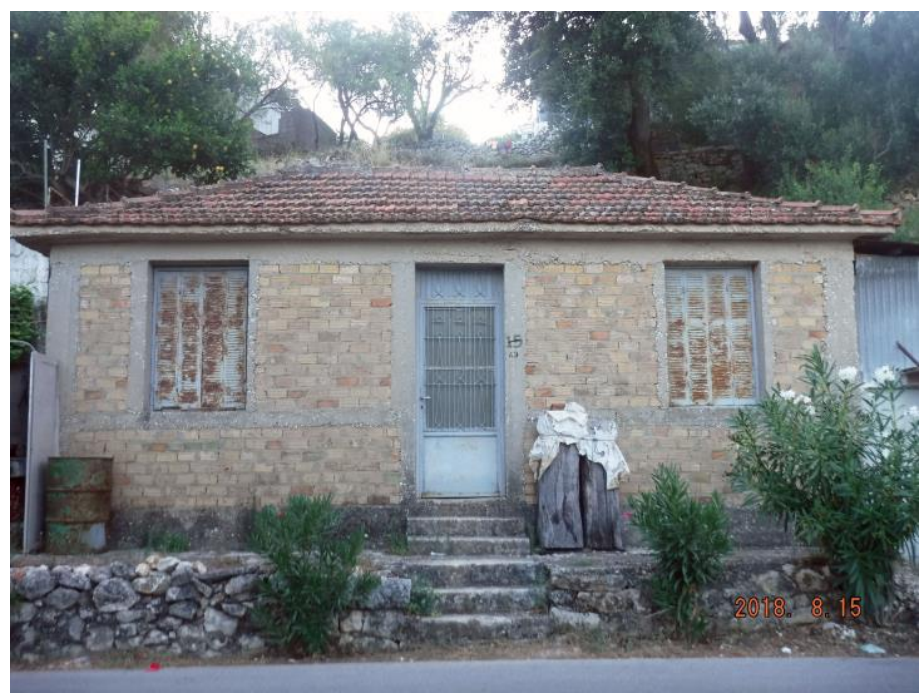

Figure 7. Confined masonry one-storey house in Pastra, with fired-clay bricks, in present condition. 


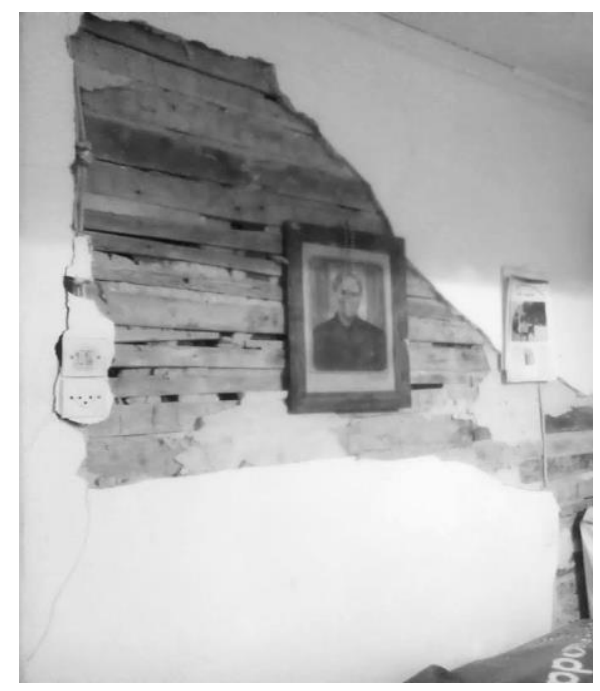

Figure 8. Morofinto wall.

\section{On "arogi" construction method}

The structural system proposed, as a result of a broad collaboration, can be classified today as reinforced confined masonry (RCM). Each architectural type was accompanied by two detailed applications of the same structural system, described in separate drawings: in the first case, masonry walls were to be made using fired-clay bricks and in the other using concrete blocks [figure 8]. It can be stated from field observation, that in Kefalonia most arogi buildings are built using concrete blocks, especially produced in order to obtain high compressive strength.

\subsubsection{Description of concrete-block masonry one-storey houses}

In most of the cases, arogi buildings are made of concrete blocks confined masonry and covered with a timber roof. In that case, wall thickness is about $0.25 \mathrm{~m}$ built in a single wythe. The concrete block's dimensions are 340(L)x250(H)x140(W) and has two large vertical holes. Reinforcing bars penetrated vertically through these voids and were filled with concrete. Along with the vertical ones, horizontal reinforcement bars were placed in the middle of the masonry width, in every bed joint between blocks [8] (p.4), [9] (p.5). Horizontal bars were anchored in vertical concrete zones that form the pilasters of the wall openings, as well as in the corner tie-columns, where vertical walls intersect [9] (p.9).

When dividing walls do not follow the same structural system, they are made of timber frames, covered by diagonal lath sheathing with plaster coating. The void between the timber beams and columns were filled with a mixture of mud with animal hair or straw. This kind of wall is called

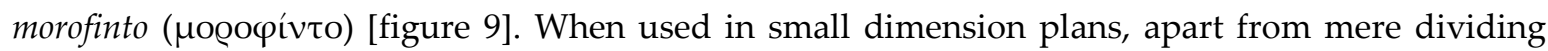
walls, they played their part in supporting the timber roof, along with the perimeter walls.

\subsubsection{Description of fired clay-bricks masonry one-storey houses}

In fired clay bricks masonry, wall thickness was about $0.25 \mathrm{~cm}$ and comprised of two wythes of solid bricks. The corner and intermediate confining zones had the same thickness as the wall and were made of reinforced concrete. All the other construction details, are the same as in concrete-block masonry.

\subsubsection{A comparison between Reinforced Confined Masonry (RCM) and Reinforced Concrete (RC) frames with Infill Walls}

At a first glance, reinforced confined masonry buildings and exposed reinforced concrete frames with infill walls constructions look alike, although they constitute completely different structural systems. Although horizontal and vertical confining zones are similar to reinforced concrete (RC) 
beams and columns, yet they seem to differ significantly, when it comes to their construction method and on their static behavior [17,18] [figure 8].

- In confined masonry, block walls are built first and tie-columns are casted against the walls' sides, creating vertical zones that confine the block masonry. Additionally, horizontal reinforcement bars act as dowels, so that tie-columns are integrated into the masonry.

In $\underline{R C}$ frames with masonry infill walls frames, the RC frame is constructed first and masonry walls follow. As one construction phase is completely independent of the other, so is each part of the structure's static behavior: in RC frames there is no toothing and walls adhesion rely solely on the binding mortar, unless it is anchored through mounted dowels in the frame. The finished structure has a relatively poor uniform behavior towards in-plane forces [figure 10].

- Due to the way they are constructed, RC tie-columns and concrete blocks in confined masonry structures form a coherent surface with a satisfactory behavior towards in-plane earthquake forces. Against lateral seismic loads they act as shear walls, similar to reinforced masonry walls or RC shear walls.

That is not the case with infill walls of RC frames, which act as diagonal struts against lateral loads. Infill walls have poor adherence to RC frames, due to frequent gaps between the infill wall and the RC beams and columns. These gaps are either intentionally designed as construction tolerances or have emerged as an earthquake effect [figure 11].

- Generally, horizontal and vertical RC tie-elements in confined masonry are smaller than beams and columns in RC frames, in structures of corresponding final dimensions. Tie-columns' final dimensions in particular, come as a result of the building process and their width is definitely determined by the masonry wall. Such slender dimensions cannot provide an effective frame behavior, but are relatively elastic - also due to tie-beam-to-tie-column pinned connections.

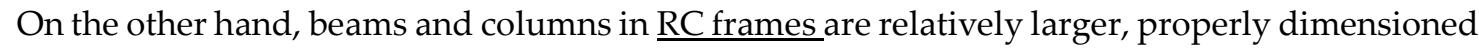
in order to act as an independent load bearing structure. RC frames' geometry, material composition and moment connections contribute to a significantly larger stiffness, when compared to that of the infill wall.

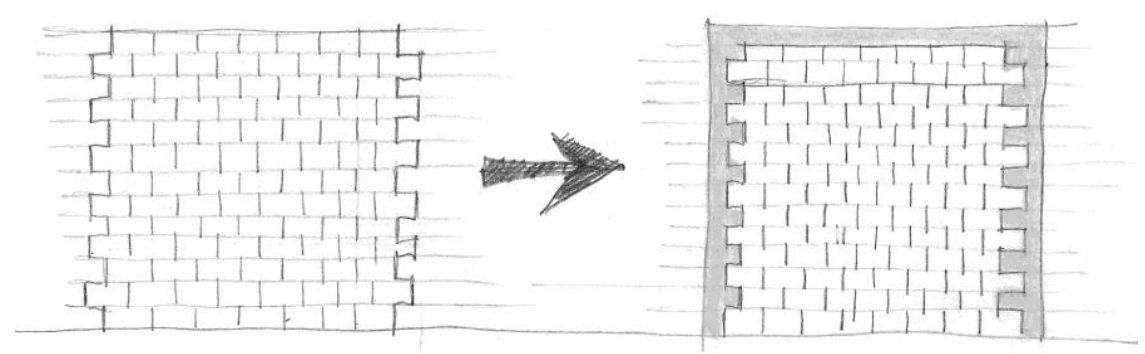

(a)

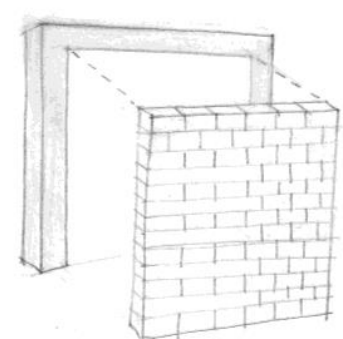

(b)

Figure 9. (a) CM confining elements; (b) RC frame with infill wall.

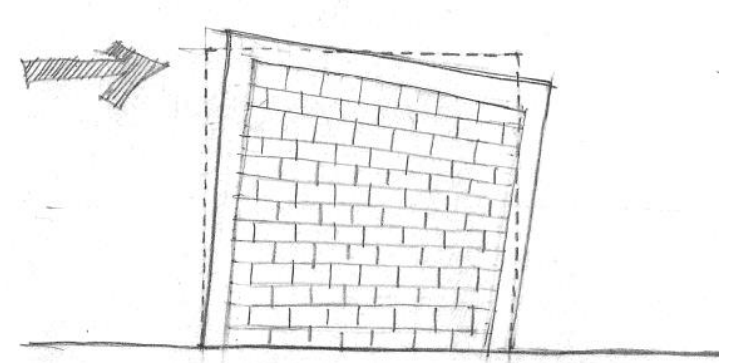

(a)

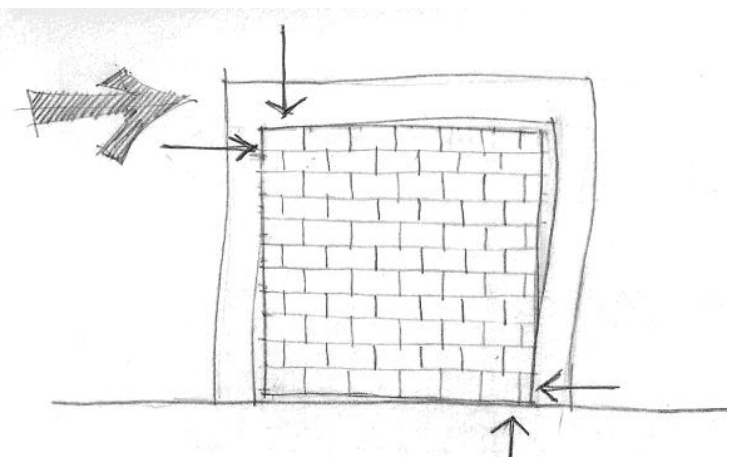

(b)

Figure 10. (a) Load bearing wall; (b) Infill wall. 
- Confined masonry construction's geometry imposes all the structural elements' - tie-beams, tiecolumns and masonry wall - cooperation in order for the masonry wall to carry the structure's dead loads, as RC tie-elements can barely carry their self-weight.

On the contrary, infill wall in RC frames mainly bear self-weight.

- In confined masonry, interior dividing walls of the same structure contribute in the total amount of confined masonry walls in one plan direction (usually, when interior walls of one plan direction are made of confined masonry, the other plan dimension is significantly elongated). Especially in the case of «arogi» buildings, morofinto walls are significantly elastic and able to absorb in-plane loads before carrying them as shear forces against perimeter walls.

- Advanced construction and supervision skills are necessary at some construction stages in confined masonry. Yet, detailing, inspection and the construction process itself require less

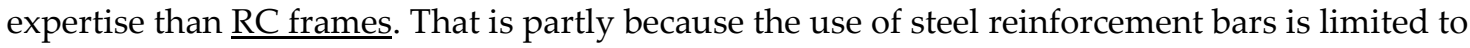
confining elements only - and not load bearing elements. - and even lower strength concrete can be used. Under normal circumstances - i.e. regular plans and well-constructed walls - confined masonry construction is a more «forgiving» building technology, that allows minor design and construction flaws, as well as material deficiences.

That is a really important fact, if one considers that during the reconstruction and although a great number of craftsmen and construction crews arrived in Kefalonia from all over the country [2] (p.24), even non-specialized civilians had to contribute in their own house construction.

\section{Discussion}

What is even more important is the way this «loose» specification building system performed more than adequately during the 2014 earthquake in Kefalonia. Original arogi buildings - which had not been subjected to alterations or additions - showed no signs of significant damage.

Recent arogi buildings' performance motivated further research on the system's behavior by F. Karantoni and S. Pantazopoulou [8] (p.5), [9] (p.7). The main objective of their analysis was the comparison of confined masonry $(\mathrm{CM})$ buildings to common unreinforced stone masonry (URM) buildings, as an alternative building system for the reconstruction of the island after the 1953 quake. Secondarily, analysis examined the effect of two different types of horizontal diaphragms on the same model, that is RC slab compared to timber roof. Comparative analysis showed that reinforced confined masonry with timber roof, as applied in «arogi» buildings, was overall the most efficient and cost-saving building technology, compared to the other structural systems that were examined.

It seems that scientific research gave numerical documentation to the instinctive trust showed by the locals towards that specific structural system and in concrete blocks as a particular building material.

Given that a great number of repair studies were launched by the occasion of the 2014 earthquake, many arogi houses and their structural condition were recorded, creating a significant archive, available for further research.

\section{Conclusions}

Apart from presenting confined masonry's benefits, the real objective of this paper is to defend arogi buildings, not only as efficient structural models, but also in a broader field, that is as architectural paradigms. The conversation about recent Kefalonian architecture is uttered with grief about the loss of impressive residences, baroque churches and every single building that narrated the island's architectural history, up until 1953. Actually, Kefalonians considered the ready-made designs as "detached from local tradition, but also uncomfortable, neither modern, nor traditional... neither majestic, nor contemporary..." [4] (p.247). Indeed, the available building types could not provide for variant plot settings. As it is expected, any inhabitant who could afford it, hired an architect or a civil engineer to modify the original plans - but the great majority did not reconsider the proposed structural system.

Post-earthquake buildings had absolutely no reference to former architecture and it seems that it was not only a matter of necessity. It has been stated that although in Zakynthos reconstruction 
progressed abiding by traditional morphological standards, for Kefalonia and Ithaki it was decided that new buildings - both private and public - would fully correspond with contemporary standards [7] (p.44). It could be said that these two islands were treated as a small scale building experiment, during a time of great residential changes all over the country.

Arogi buildings austere morphology can be considered as a rupture in kefalonian architectural tradition as it was formed until 1953, but structurally they seem more like an inevitable bridge: as reinforced confined masonry (RCM) buildings stand between traditional unreinforced stone masonry (USM) buildings and contemporary RC frame buildings with fired-clay infill walls. Stone masonry structures are basically non-engineered, as they incorporate empirical building techniques, which are inherited rather than academically taught. Traditional techniques make the best use of available materials, considering the particularities of each specific site, climate and the seismic activity of the area.

On the other hand, contemporary structures are definitely designed and built by professionals. Their building techniques and materials are based on applied scientific knowledge, which is both theoretically and empirically tested and certified. Building technology is driven by design principles rather than a resource-saving and effective method.

Arogi buildings stand in the middle of this dissension. Although designed by professionals, they were subjected to several alterations either studied in the designers' office or conducted on the spot. The particular technology itself allowed for such modifications, as it is a relatively flexible building method, that blends typical and intuitive knowledge, builds new materials in traditional ways. Just after the 1953 quake, aroges responded effectively to emergent conditions: massive housing demand, limited budgets and construction flexibility.

Today, having outlived 65 years of intense seismic activity, we can claim that they have become an organic part of the island, having integrated into the landscape, as their former technical character is smoothed out of everyday life. After all, their existence declares not only their structural efficiency, but the island's recent history as well.

\section{Acknowledgments etc.}

Funding: This research received no external funding

Acknowledgments: The author is thankful to the City Planning Services Office of the Municipality of Kefalonia in the Ionian Islands District that provided open access to their arogi building types archive.

She is more than grateful to Vaggelis Vallianos' Civil Engineers Office based in Lixouri of Kefalonia, who allowed full access to his building repair studies, related to damages caused by the 2014 earthquake in Kefalonia. Vaggelis Vallianos himself provided expertise that greatly assisted the research and any kind of valuable support for writing this paper. Any errors, misunderstood concepts or any other fallacies are our own and should not be attributed to the entities or professionals mentioned above.

Conflicts of Interest: The author declares no conflict of interest.

\section{References}

1. Giles D. Intensity Scales. In: Bobrowsky P.T. (eds) Encyclopedia of Natural Hazards. Encyclopedia of Earth Sciences Series. Springer, Dordrecht, 2013. https://doi.org/10.1007/978-1-4020-4399-4_198.

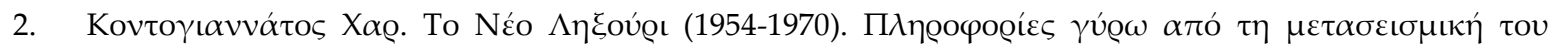

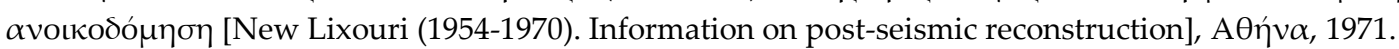

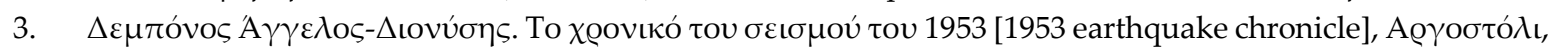
1976.

4. Legislative Decree no. 2933/27-07-1954 (GG162A): On reconstruction of earthquake stricken Ionian islands

5. Legislative Decree no. 2934/27-07-1954 (GG162A): On modification of town planning ordinances and some special orders relevant to the reconstruction of the earthquake stricken Ionian islands.

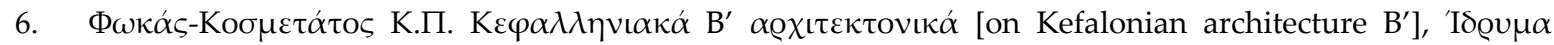

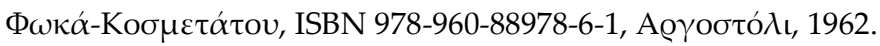

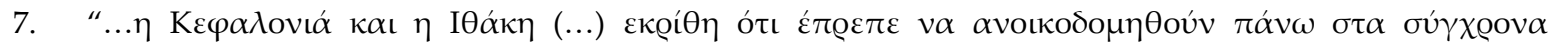

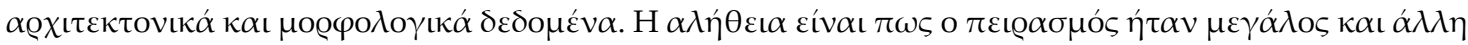




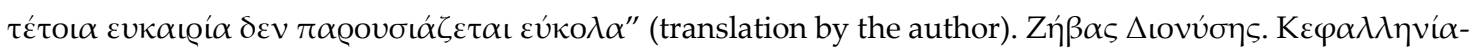

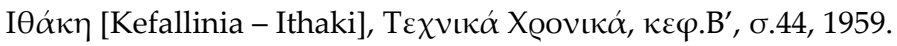

8. Karantoni F. - Pantazopoulou S. The performance of confined masonry buildings in the 2014 Cephalonia earthquakes, in Rehabend 2016, May 24-27, 2016. Burgos, Spain, 2016. Codigo: 1.7.55

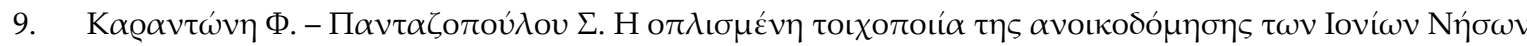

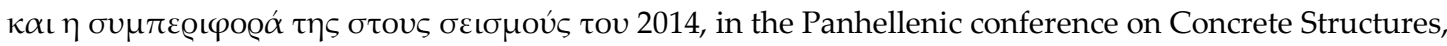
Thessaloniki, 10-12 of November 2016. http://library.tee.gr/digital/m2622/m2622_karantoni.pdf, (last accessed 20.12.2018).

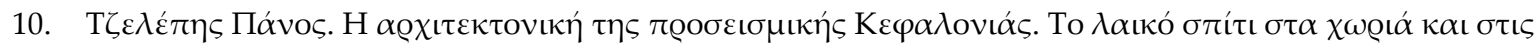
$\pi$ ó $\lambda \varepsilon ı \varsigma$ [Architecture in Kefalonia before the erthequake. The Traditional house in villages and towns],

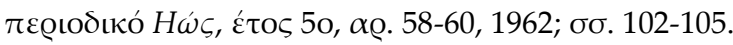

11. Svoronou Angèle. Traditional Cephalonian Architecture, The Fokas-Kosmetatos Foundation, Argostoli, 1999.

12. M M

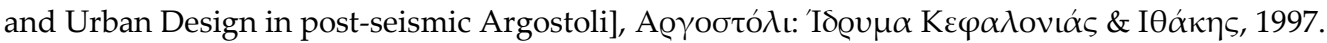

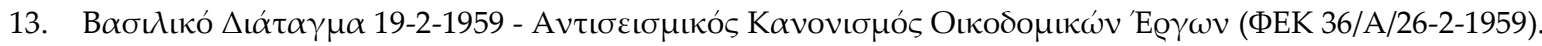
Royal Decree of 19-2-1959 (GG36A/26-2-1959) - Anti-seismic Building Regulation

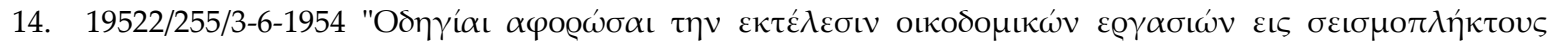

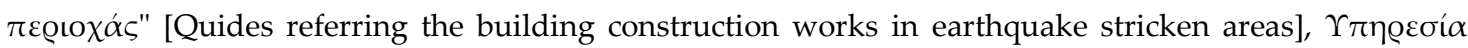
Oıкıбнои́

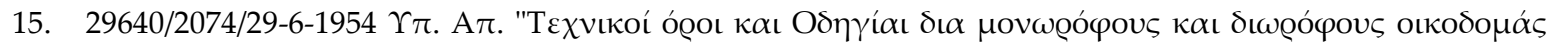

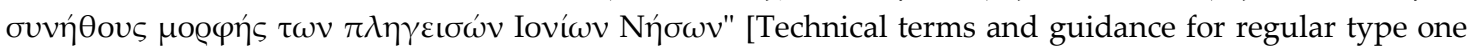
and two-storey buildings in stricken Ionian Islands], (Г.A.ट.I.N.)

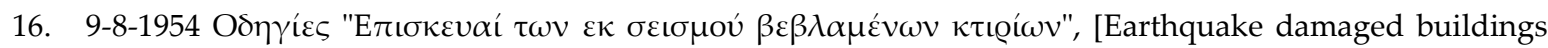
repairs], (Г.A.इ.I.N.)

17. Seismic design quide for low-rise confined masonry buildings, in Confined Masonry Network, http://www.confinedmasonry.org/wp-content/uploads/2009/09/ConfinedMasonryDesignGuide82011.pdf (last accessed 06.12.2018).

18. Earthquake Engineering Research Institute, https://www.eeri.org, (last accessed 06.12.2018). 